\title{
Concepções sobre o Behaviorismo Radical nas Publicações da Folha de S.Paulo
}

\author{
Marcos Spector Azoubel ${ }^{1}$ \\ André Thiago Saconatto ${ }^{1,2}$ \\ ${ }^{1}$ Pontifícia Universidade Católica de São Paulo, SP, Brasil. $\quad$ 'Pontifícia Universidade Católica de São Paulo, SP, Brasil. \\ ${ }^{2}$ Centro Universitário São Camilo, SP, Brasil.
}

Resumo: Frequentemente, o behaviorismo radical e a análise do comportamento são apresentados na mídia por meio de estereótipos negativos, possivelmente atravancando a difusão de suas propostas aos potenciais beneficiários. Com base nisso, o objetivo deste trabalho é caracterizar as publicações do jornal Folha de S.Paulo sobre behaviorismo radical e análise do comportamento desde a sua fundação em 192, até 2015. Para tal, 227 parágrafos presentes no jornal que continham os termos Skinner ou behaviorismo foram selecionados para análise. De forma geral, foram encontrados trechos contendo críticas ao behaviorismo radical que expuseram equívocos históricos e conceituais, problematizaram o este campo de estudo, apresentaram algum aspecto correto e/ou apresentaram o termo "behaviorismo" de forma genérica. Foram identificados tópicos especialmente mal compreendidos: a análise do comportamento como legitimadora do controle, ultrapassada pelas teorias cognitivistas, capaz de explicar apenas comportamentos simples ou de animais não-humanos e interessada apenas em comportamentos observáveis. Recomenda-se que behavioristas radicais comuniquem suas propostas com ênfase em seu caráter de denúncia do controle como uma característica inerente às relações comportamentais de uma ciência viva em constante desenvolvimento e de uma abordagem interessada em lidar com quaisquer comportamentos, que aconteçam dentro ou fora da pele.

Palavras-chave: Análise do Comportamento, Comportamentalismo, Comunicação Científica, Skinner, Mídia Popular.

\section{Conceptions about Radical Behaviorism in Folha de S.Paulo's Publications}

\begin{abstract}
Often radical behaviorism and behavior analysis are presented in the media by means of negative stereotypes, thus possibly making harder the diffusion of its proposals to potential target audience. Taking that into account, this paper categorized publications from the newspaper Folha de S.Paulo since its foundation, in 1921, until 2015, regarding radical behaviorism and behavior analysis. To reach such goal, 227 paragraphs were selected containing the terms Skinner or behaviorism from the newspaper. In general, excerpts that criticized radical behaviorism, parts that exposed historical and conceptual misconception, that problematized radical behaviorism, that showed some correct aspect and that presented the term behaviorism in a generic way were found. Some specially misunderstood topics were identified: the view of behavior analysis as an approach that defends control, outdated and overcome by cognitive theories, is only capable of explaining simple human or non-human behavior and interested in observable behavior. We recommend behavior analysts that communicate their proposals with an emphasis on control as an inherent characteristic of behavioral relations to take into account it is a constantly evolving science and an approach interested in dealing with any behavior, whether occurring over or under the skin.
\end{abstract}

Keywords: Behavior Analysis, Behaviorism, Mass Media, Scientific Communication, Skinner. 


\title{
Concepciones acerca del Conductismo Radical en las Publicaciones de Folha de S.Paulo
}

\begin{abstract}
Resumen: El análisis conductual y el conductismo radical son presentados a menudo en los medios de comunicación mediante estereotipos negativos, posiblemente dificultando la difusión de sus propuestas a los potenciales beneficiarios. Basándose en esto, el objetivo de este trabajo fue caracterizar las publicaciones del diario Folh a de S.Paulo sobre el análisis conductual y el conductismo radical desde su fundación, en 1921, hasta 2015. Para ello, se seleccionaran para análisis 227 párrafos presentes en el diario, que contenían las palabras Skinner o conductismo. En general, se encontraron extractos que hicieron críticas al conductismo radical, que expusieron equívocos históricos y conceptuales, que problematizaron el conductismo radical, que presentaron algún aspecto correcto y que presentaron el término "conductismo" de manera genérica. Se identificó tópicos especialmente incomprendidos: la perspectiva de análisis de la conducta como un enfoque psicológico defensor del control, ultrapasada y superada por las teorías cognitivistas, capaz de explicar solo los comportamientos simples o de animales no humanos e interesada solamente en comportamientos observables. Se recomienda que conductistas radicales comuniquen sus propuestas con énfasis en su carácter de denuncia del control como una característica inherente a las relaciones comportamentales, de una ciencia viva, en desarrollo continuo, y de un enfoque psicológico interesado en tratar cualquier comportamiento, que ocurra dentro o fuera de la piel.
\end{abstract}

Palabras clave: Análisis de la Conducta, Conductismo, Prensa Popular, Comunicación Científica, Skinner.

Democratizar e divulgar os conhecimentos produzidos pelas disciplinas científicas para o público leigo (Bueno, 2010) e motivar o interesse sobre ciências nos leitores (Pedrosa \& Santos, 2016) são objetivos da divulgação científica. Isso costuma ser feito por meio de variados veículos de comunicação voltados a público não especializado como programas de televisão, jornais, revistas, livros, rádio e jornalismo digital. Apesar da relevância dos trabalhos de divulgação científica, écomum, de acordo com PedrosaeSantos (2016), que a tarefa seja realizada por profissionais do jornalismo, que apresentam pouco domínio dos procedimentos científicos e dos conhecimentos produzidos por eles, acarretando ocasionalmente em divulgação imprecisa dos conceitos científicos.

A maneira como o conhecimento científico é divulgado na mídia popular é um dos fatores que influenciam a percepção pública da população em geral sobre as ciências (Righetti, 2018). Por isso, torna-se importante analisar como a mídia tem divulgado informações sobre as diversas disciplinas científicas (Morris, 1985).

A análise do comportamento - ciência apoiada nos pressupostos filosóficos do behaviorismo radical
(Skinner, 1974), fundada por B. F. Skinner (1904-1990) é uma abordagem psicológica pouco conhecida pelo público em geral. Normalmente, essa abordagem é apresentada por meio de estereótipos negativos com foco numa visão distorcida, em especial as noções de controle e de controle aversivo (Arntzen, Lokke, Lokke \& Eilertsen, 2010; Azoubel \& Abbud, 2017; Freedman, 2016; Gioia, 2001; Miraldo, 1985; Rodrigues, 1999).

A despeito de Skinner ser amplamente reconhecido como um dos mais notáveis e influentes pensadores do século XX (Mogdil \& Mogdil, 1987), sua obra tem despertado grande número de controvérsias ao longo dos anos. Porém, de acordo com o autor (Skinner, 1973, 1974), a maior parte dessas polêmicas são fruto de incompreensões das suas propostas teóricas, metodológicas e tecnológicas. Por isso, Skinner dedicou-se a publicar diversos trabalhos em análise do comportamento dirigidos ao público leigo por meio jornais, revistas, entrevistas e livros que traduziam as bases do behaviorismo radical e da análise do comportamento para linguagem coloquial (Rutherford, 2004); por exemplo, no Brasil, o autor concedeu duas entrevistas à revista Veja (Azoubel \& Abbud, 2017). 
Por mais que Skinner tenha tentado assiduamente comunicar-se com o público em geral, as críticas baseadas em incompreensões continuaram e continuam acompanhando os analistas do comportamento desde tal data. Diversos autores apontaram que as compreensões equivocadas sobre a análise do comportamento e o behaviorismo radical resultam em empecilhos para a propagação de suas propostas conceituais e tecnológicas (Azoubel \& Abbud, 2017; Freedman, 2016; Friman, 2014; Gioia, 2001; Guimarães, 2003; Morris, 1985; Normand, 2014; Rodrigues, 2006; Weber, 2002). Tendo isso em vista, essa questão tem sido foco de variadas publicações de analistas do comportamento que visaram identificar equívocos sobre o behaviorismo radical e a análise do comportamento (Azoubel \& Abbud, 2017; Gioia, 2001; Guimarães, 2003; Rodrigues, 2006; Weber, 2002) e delinear estratégias que aumentem o impacto das propostas da análise do comportamento na sociedade (Freedman, 2016; Friman, 2014; Morris, 1985; Normand, 2014; Smith, 2016).

Para examinar o que foi publicado na revista Veja, um dos meios mais populares de circulação de informações no Brasil, sobre behaviorismo radical e análise do comportamento, Azoubel e Abbud (2017) buscaram pelos termos Skinner, análise do comportamento e behaviorismo no acervo digital desta revista. Após aplicação dos critérios de exclusão, foram analisados doze trechos que tratavam sobre behaviorismo radical e análise do comportamento. Destes, onze trechos apresentavam equívocos históricos (e.g., afirmações de que Skinner seria psicanalista e fundador do behaviorismo, sem especificação do behaviorismo radical) ou conceituais (e.g., alegações de que o behaviorismo lida apenas com fenômenos observáveis e de que defende o uso de práticas coercitivas). Futuras pesquisas que identifiquem o que é veiculado sobre a análise do comportamento em meios de comunicação populares podem ajudar a compreender de forma mais ampla a visão do público em geral sobre a análise do comportamento e, com isso, planejar estratégias adequadas de comunicação e tentar avaliar de que maneira os próprios analistas do comportamento podem ter contribuído para a construção de concepções negativas sobre suas práticas e, então, exercer a autocrítica.

Com base no que foi exposto até aqui, o objetivo deste trabalho é descrever sistematicamente e examinar criticamente as publicações do jornal Folha de S.Paulo sobre behaviorismo radical e análise do comportamento, originalmente publicadas em versão impressa, desde a sua fundação, em 1921, até o ano de 2015. Este veículo de comunicação foi escolhido por possuir circulação nacional e por ser o jornal mais vendido do Brasil desde a década de 1980, o que demonstra sua importância no cenário nacional.

\section{Método}

\section{Fonte de informações}

O "Acervo Folha" (https://acervo.folha.com.br/ index.do) foi utilizado como fonte de informações. Essa fonte disponibiliza gratuitamente todas as edições diárias do jornal, desde a sua primeira publicação em 1921.

\section{Procedimento de busca}

Na página inicial do "Acervo Folha" foi selecionada a opção "busca detalhada". No campo "com pelo menos uma das palavras" foram inseridos os termos Skinner e behaviorismo. Como resultado da busca, foram encontradas 405 entradas. Cada entrada consistia em uma imagem digitalizada de duas folhas do jornal publicadas entre 1921 e 2015.

\section{Critérios de exclusão}

Foram excluídos os trechos em que Skinner ou behaviorismo foram apenas citados brevemente; que não continham observações sobre eles, apenas citando-os nominalmente (e.g., alguns trechos apenas listaram diversas áreas da Psicologia, incluído aí o behaviorismo); ou foram citadas outras pessoas, personagens ou instituições com nome ou sobrenome "Skinner". Ao fim dos procedimentos de exclusão, restaram 104 entradas que continham 227 parágrafos selecionados para análise.

\section{Procedimento de análise}

Os parágrafos em que os termos selecionados apareceram e que não se enquadraram nos critérios de exclusão foram transcritos integralmente em uma planilha do Microsoft Excel2010. Também foram registradas a página em que cada termo apareceu, a data de publicação e algumas informações gerais sobre o texto do qual o trecho fazia parte (i.e., autor[es] do texto; assuntos abordados durante o texto; referências a Skinner, à análise do comportamento ou ao behaviorismo radical; relações entre o trecho selecionado e o restante do texto).

Após a coleta das informações, os autores deste artigo leram-nas conjuntamente (um ao lado do 
outro, em voz alta). Após a leitura em voz alta, os autores discutiam em qual(is) categoria(s) cada trecho pertencia. Em caso de discordância, cada um expunha seus argumentos para esclarecer suas respectivas posições e, baseando-se nestes argumentos, os autores decidiam a pertinência de cada trecho a uma ou mais categorias de análise estabelecidas. Quando nenhuma das categorias pareceu adequada, criaram-se novas categorias. Após consenso entre os pesquisadores, cada trecho foi caracterizado conforme uma ou mais categorias e subcategorias a seguir:

- equívoco sobre behaviorismo radical, análise do comportamento ou Skinner: os trechos foram considerados como contendo equívocos históricos nos casos em que apresentaram equívocos em relação a aspectos históricos da análise do comportamento, do behaviorismo radical ou da vida e obra de Skinner. Os equívocos históricos foram categorizados em: alegação do fim do behaviorismo radical, indicação de Skinner como fundador do behaviorismo, equivoco sobre propostas tecnológicas e equívoco sobre a formação acadêmica de Skinner. Trechos que apresentaram equívocos relacionados aos conceitos e princípios básicos e os pressupostos filosóficos da área foram agrupados como contendo equívocos conceituais. Tais equívocos foram categorizados em: afirmação de que o behaviorismo radical rejeita qualquer forma de introspecção, alegação de que resultados de pesquisas com não humanos não seriam generalizáveis para humanos, suposição de rejeição por parte do behaviorismo radical de qualquer dotação inata, atribuição ao behaviorismo radical de uma posição antiteórica, indicação do paradigma estímulo-resposta como unidade básica de análise da análise do comportamento, utilização imprecisa dos termos analítico-comportamentais e declaração de que o behaviorismo radical defende o controle. Os critérios utilizados para definir os trechos como equivocados se basearam em textos de Skinner que apresentam posições contrárias às consideradas equivocadas descritas nos trechos analisados. Os argumentos e o esclarecimento dos equívocos estão presentes na seção de Discussão;

- apresentação de aspectos corretos: reúne trechos que apresentaram informações corretas sobre Skinner, análise do comportamento e/ou behaviorismo radical. As subcategorias foram citação correta para justificar argumentos, descrição correta de aspectos biográficos ou bibliográficos sobre Skinner e exposição correta de aspectos conceituais;

- crítica ao behaviorismo radical, à análise do comportamento ou a Skinner. as emissões de avaliações, de qualificações ou de opiniões sobre behaviorismo radical, análise do comportamento ou Skinner foram considerados posicionamentos críticos. Foram categorizados como contendo crítica positiva os trechos que apresentaram opiniões favoráveis à área; crítica sobre o controle do comportamento, os trechos que expuseram opiniões desfavoráveis à noção de controle no behaviorismo; crítica à superficialidade, os trechos que expressaram opiniões contrárias ao alcance da teoria analítico-comportamental aos problemas humanos complexos; atribuição de valor inferior, qualificando o behaviorismo radical como uma abordagem psicológica inferior às demais; metacrítica, os trechos que criticaram as críticas à área. Trechos que apresentavam adjetivos indicando controvérsia e repúdio a Skinner entraram nas subcategorias controverso/repudiado, e em influente entraram os trechos que atribuíram adjetivos a Skinner que indicaram a influência de suas contribuições para Psicologia ou para a sociedade;

- problematização de algum aspecto sobre behaviorismo radical, análise do comportamento ou Skinner: esta categoria engloba trechos que apresentaram dois ou mais pontos polêmicos ou divergentes, sem exposição de posicionamento por parte do autor em favor de um dos pontos (quando o autor posicionou-se a favor de um dos pontos, o trecho foi categorizado como possuindo uma crítica). As subcategorias utilizadas foram problematização sobre liberdade $e$ controle, que englobou trechos em que foram apresentadas posições distintas sobre liberdade e controle e problematização sobre as diferenças entre o behaviorismo radical e outras correntes de pensamento, que reuniu trechos tratando de diferenças entre posições behavioristas radicais e de outras correntes filosóficas ou psicológicas;

- utilização do termo "behaviorismo" de forma genérica: os trechos que não explicitaram diretamente sobre qual behaviorismo se referiram, mas forneceram alguma informação que permitiu identificar se tratar sobre behaviorismo radical foram incluídos na categoria identificável como tratando do behaviorismo radical; para os casos em que foi possível identificar a menção a outra 
teoria behaviorista, os trechos foram inseridos na categoria identificável como tratando de outro behaviorismo; os trechos que não forneceram informações suficientes para identificar qual behaviorismo foi abordado foram acrescentados à categoria não identificável.

\section{Resultados e discussão}

Como é possível notar na Figura 1, a primeira menção à análise do comportamento ou ao behaviorismo radical encontrada na Folha de S.Paulo data de 1961. Talvez o aparecimento relativamente tardio de citações à área se deva ao fato de este ter sido o ano da primeira visita ao Brasil de Fred Keller como professor visitante na Universidade de São Paulo, e de não existirem, antes disso, materiais sobre análise do comportamento publicados no país (Todorov, 2003). Como exemplo, a primeira edição do livro Ciência e Comportamento Humano foi publicada no Brasil apenas em 1967.

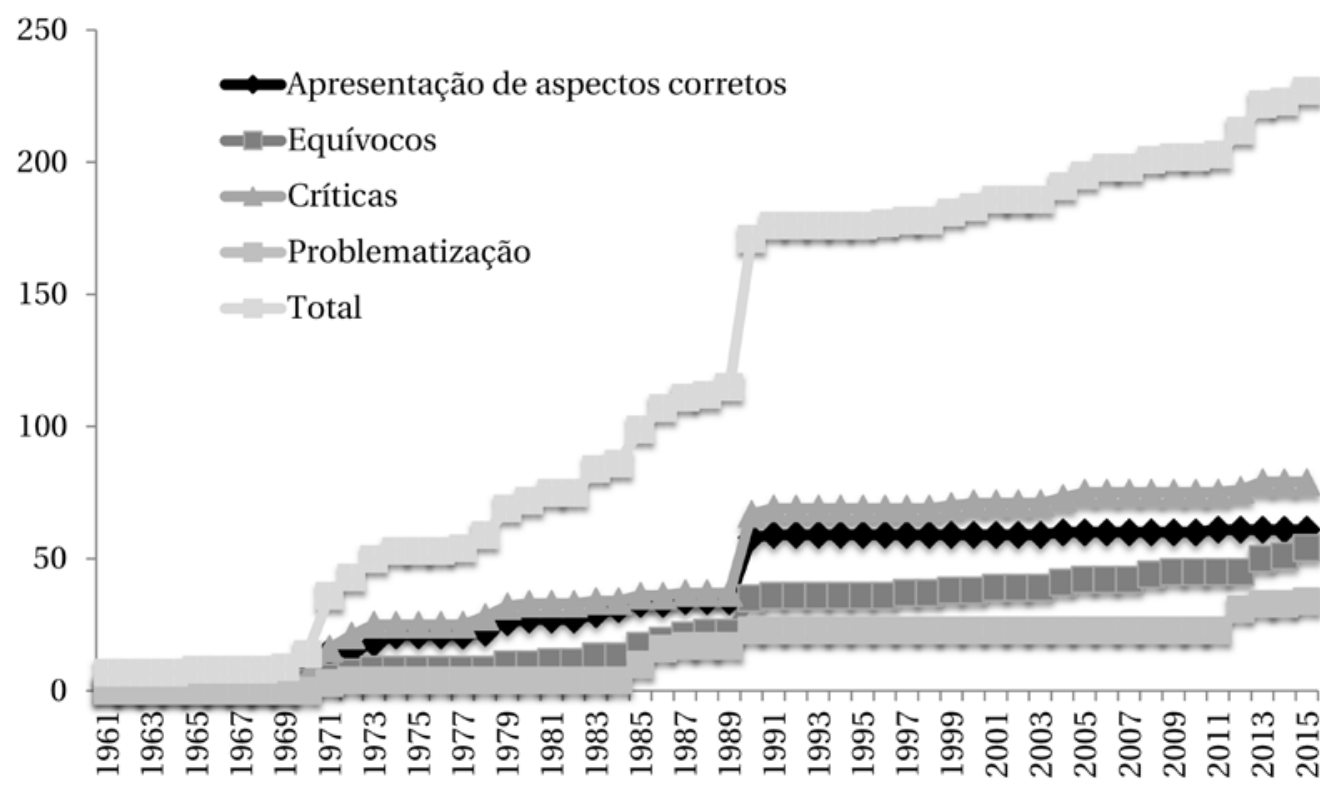

Figura 1

Ao longo dos anos, número acumulado de trechos em cada categoria e número total de trechos.

Conforme mostra a Figura 1, até o ano de 1971 a apresentação de aspectos corretos foi a categoria mais recorrente nos trechos analisados. Entre 1972 e 1989 houve alternação entre esta e a categoria críticas ao behaviorismo radical como a de maior ocorrência. Por fim, a partir de 1990 a categoria de crítica ao behaviorismo radical ultrapassou a categoria de apresentação de aspectos corretos $\mathrm{e}$, ao final do período analisado, foi a que ocorreu no maior número de trechos $(\mathrm{N}=71)$, seguida pela de aspectos corretos $(\mathrm{N}=61)$. No decorrer dos anos, a categoria equívocos sobre o behaviorismo radical e de utilização do termo "behaviorismo" de forma genérica se alternaram como a terceira e a quarta categorias em número de ocorrência, mas em 2015 a ocorrência de equívocos foi a terceira em número de ocorrências nos trechos $(\mathrm{N}=54)$, enquanto a categoria de uso do termo "behaviorismo" de maneira genérica apareceu como a quarta categoria mais recorrente $(\mathrm{N}=53)$. Por último, a categoria de problematização de aspectos sobre o behaviorismo radical $(\mathrm{N}=36)$ foi a menos recorrente dentre as categorias durante o período analisado.

Destaca-se que Skinner faleceu em 1990, aspecto que coincide com o ano em que houve a maior ocorrência de trechos que trataram sobre o behaviorismo radical e a análise do comportamento devido à divulgação de sua morte. Interessante notar que, como é possível observar na Figura 1, enquanto Skinner estava vivo havia mais ocorrências e de forma mais sistemáticas quando comparado ao período post mortem. Isso vai ao encontro do aspecto apontado por Rutherford (2004), que salientou a sua grande visibilidade nos públicos acadêmico e popular, possivelmente 
produzida pela sistemática divulgação de sua teoria por meio da publicação de artigos em jornais e revistas e de livros voltados a não especialistas em análise do comportamento e behaviorismo radical.

Para construção da Figura 1, foi contabilizado o número de trechos que se enquadraram em cada categoria geral, para que fosse possível comparar tal número com o número total, fornecendo uma caracterização geral dos trechos analisados. Para as análises apresentadas a seguir, levou-se em conta o número de ocorrências de cada categoria e subcategoria nos trechos, de forma que cada trecho pôde ser categorizado conforme mais de uma subcategoria, ultrapassando os números expostos na Figura 1.

Contabilizadas as ocorrências das subcategorias nos trechos examinados, foi possível notar que o maior número de ocorrências foi das subcategorias de críticas, com 84 . Em seguida vieram as subcategorias de equívocos e de apresentação de aspectos corretos, com sessenta ocorrências cada. Por fim, para as categorias de utilização do termo "behaviorismo" de forma genérica e problematização de algum aspecto sobre o behaviorismo radical não houve incidência de mais de uma subcategoria por trecho, de forma que a primeira se manteve com 53 ocorrências e a segunda com 36 .
Dentre os equívocos conceituais, foram encontrados dois trechos com afirmações de que o behaviorismo radical rejeitava qualquer tipo de introspecção; três trechos apresentaram equívocos sobre a suposta superficialidade, afirmando que os estudos da análise do comportamento se limitam a sujeitos não-humanos e que, por isso, seus princípios não serviriam para compreensão do comportamento do indivíduo; dois trechos expuseram equívocos sobre a suposta negação de qualquer dotação inata por parte do behaviorismo radical; seis trechos atribuíram ao behaviorismo radical suposta posição antiteórica de ciência; quatro trechos deram a entender que a unidade básica de análise da análise do comportamento seriam as relações estímulo-resposta; dezessete trechos utilizaram conceitos básicos analítico-comportamentais de maneira imprecisa, apresentando interpretações mentalistas (atribuição de causas de comportamentos a eventos internos ou com natureza não-física) e/ou teleológicas (atribuições de causas futuras a comportamentos do presente), ou atribuindo conceitos de outras áreas à análise do comportamento; cinco trechos afirmaram que o behaviorismo radical defende o controle. Exemplos de trechos agrupados conforme cada subcategoria estão dispostos na Quadro 1.

\section{Quadro 1}

Apresentação de trechos que exemplificam as subcategorias de equívocos conceituais.

\begin{tabular}{|c|c|}
\hline Trecho que exemplifica a subcategoria & Subcategoria \\
\hline $\begin{array}{l}\text { Quem com mais força pregou contra a antropomorfização foram os behavioristas, } \\
\text { liderados por B. F. Skinner, para os quais, em nome da parcimônia explicativa, toda } \\
\text { forma de introspecção deveria ser banida. (Schwartsman, 2013, p. A2) }\end{array}$ & $\begin{array}{l}\text { Afirmação de que o } \\
\text { behaviorismo radical } \\
\text { rejeita a introspecção. }\end{array}$ \\
\hline $\begin{array}{l}\text { Faz parte do arsenal de venenos da corrente que em psicologia se opõe aos } \\
\text { behavioristas do dr. Skinner, os quais insistem em pesquisar comportamento humano } \\
\text { produzindo reflexos em animais engaiolados. (Essa corrente insiste em tomar o } \\
\text { Homem como um conjunto ou uma soma de reflexos e ele não é isso. Sobretudo não } \\
\text { é um rato nem um coelho, embora haja momentos, cada vez mais frequentes em que } \\
\text { nos vemos obrigados a reconhecer que esse mamífero superior se esforça por ficar } \\
\text { intelectualmente muitos furos abaixo desses estúpidos roedores). (Pereira, 1981, p. 6) }\end{array}$ & $\begin{array}{l}\text { Alegação de que } \\
\text { resultados de pesquisas } \\
\text { com não humanos não } \\
\text { seriam generalizáveis } \\
\text { para humanos. }\end{array}$ \\
\hline $\begin{array}{l}\text { Duas posições extremas são, portanto, frequentes. De um lado, pressupondo uma } \\
\text { influência predominante da herança biológica, alguns etólogos e geneticistas } \\
\text { advogam um verdadeiro determinismo cromossômico. No extremo oposto, } \\
\text { a antropologia cultural e os psicólogos comportamentalistas (behavioristas) } \\
\text { minimizam a importância da hereditariedade, chegando admitir implicitamente, } \\
\text { como Skinner e seus seguidores, ou explicitamente como Montagu, Mead, Boas } \\
\text { e outros antropólogos que o homem é integralmente produto do meio, a "tabula } \\
\text { rasa"dos anos 50. (Leite, 1983, p. 20) }\end{array}$ & $\begin{array}{l}\text { Suposição de rejeição por } \\
\text { parte do behaviorismo } \\
\text { radical de qualquer } \\
\text { dotação inata. }\end{array}$ \\
\hline
\end{tabular}




\begin{tabular}{|c|c|}
\hline Trecho que exemplifica a subcategoria & Subcategoria \\
\hline $\begin{array}{l}\text { Para começo de conversa, Skinner não "criou" nada. Descobriu. Ele jamais negou } \\
\text { a vida interior das pessoas, como quer o jornalista; ao contrário, tentou estudá-la. } \\
\text { Nunca lançou teoria alguma, pois era avesso a teorias, e muito menos confundiu } \\
\text { ratos com gente, a não ser na imaginação do jornalista. (Stamirowski, 1990, p. A-3) }\end{array}$ & $\begin{array}{l}\text { Atribuição ao behaviorismo } \\
\text { radical de uma posição } \\
\text { anti-teórica. }\end{array}$ \\
\hline $\begin{array}{l}\text { A escola de pensamento da psicologia E-R (estímulo-resposta) foi fundada por } \\
\text { B. F. Skinner. A tese baseia-se no behaviorismo descritivo. (Folha de S.Paulo, 1991, p. 7) }\end{array}$ & $\begin{array}{l}\text { Indicação do paradigma } \\
\text { estímulo-resposta } \\
\text { como unidade básica } \\
\text { de análise da análise do } \\
\text { comportamento. }\end{array}$ \\
\hline $\begin{array}{l}\text { Considerado pelo doutor Skinner e outros psicólogos menores como uma das grandes } \\
\text { causas do fracasso no vestibular, o nervosismo e a falta de autoconfiança podem } \\
\text { ser evitados, desde que o aluno faça higiene mental e vá para o exame confiante no } \\
\text { sucesso, através da mentalização constante de que “já passei” e que não precisa, assim, } \\
\text { temer o fracasso naquele difícil testem sob o aspecto emocional. (Leminski, 1986, p. 38) }\end{array}$ & $\begin{array}{l}\text { Utilização imprecisa } \\
\text { dos conceitos analítico- } \\
\text { comportamentais. }\end{array}$ \\
\hline $\begin{array}{l}\text { "Porque as pessoas têm maus hábitos, vamos mudar seus comportamentos", } \\
\text { abordagem difundida pelo comportamentalismo desde 1950, com Skinner } \\
\text { [psicólogo norte-americano], que dizia que a liberdade é um luxo que a } \\
\text { humanidade não pode ter, pois, se as pessoas fazem o que querem, elas terão maus } \\
\text { hábitos. (Ramon, 2008, p. 8) }\end{array}$ & $\begin{array}{l}\text { Declaração de que o } \\
\text { behaviorismo radical } \\
\text { defende o controle. }\end{array}$ \\
\hline
\end{tabular}

Ao contrário do que foi veiculado nesses trechos, o behaviorismo radical e a análise do comportamento propõem o estudo de eventos privados, observáveis por apenas um organismo, mas se baseiam no princípio de que tais eventos possuem natureza física, como quaisquer outros eventos (Skinner, 1953/1965, 1974).

Essas vertentes acreditam em certa continuidade entre os organismos, que permite a compreensão de princípios comportamentais básicos a partir da investigação do comportamento de animais não-humanos, mas realizam estudos também com participantes humanos (Skinner, 1953/1965, 1974); defendem também que o comportamento humano é produto das histórias filogenética, ontogenética e cultural de seleção pelas consequências (Skinner, 1981), de forma a incluir a dotação genética na determinação dos comportamentos; afirmam que a construção de teorias científicas é tarefa imprescindível do fazer científico, apesar de rejeitarem teorias que apelem a explicações de eventos físicos a eventos não-físicos (Skinner, 1950). Esses campos de estudos utilizam a contingência comportamental de três termos (estímulos antecedentes-resposta-estímulos subsequentes) como unidade analítica básica da análise do comportamento operante (Skinner, 1953/1965, 1974). A análise do comportamento e o behaviorsimo radical defendem que as causas dos comportamentos estão na história de interação entre organismo e ambiente e rejeitam a atribuição de causalidade de comportamentos a constructos internos ou a eventos futuros (Skinner, 1953/1965, 1974) e denunciam a existência de relações de controle, entendendo que o homem é produto e produtor de si e do seu mundo, capaz de deliberar sobre o seu futuro por meio do planejamento e do autogoverno (Micheletto \& Sério, 1993; Pessotti, 2016). Dessa maneira, de acordo com Skinner (1955/1961), ao contrário de defender que o comportamento precisa ser controlado, caberia ao behaviorismo radical expor as relações de controle comportamental, demonstrando o controle como uma característica inerente às relações entre eventos do mundo, tais como as relações comportamentais entre eventos antecedentes, respostas e eventos subsequentes, tornando os sujeitos mais aptos a tomarem rumo de suas vidas ao se tornarem conscientes de tais variáveis de controle.

Em relação aos equívocos históricos, quatro trechos afirmaram que a teoria behaviorista radical deixou de existir depois das críticas de Chomsky ou do surgimento da psicologia cognitivista; dez trechos apresentaram a informação de que Skinner teria sido o fundador do "behaviorismo"; cinco trechos apresentaram erros sobre aspectos históricos de propostas tecnológicas de Skinner ou atribuíram a ele a criação 
de tecnologias que não lhe cabiam; dois trechos informaram equívocos sobre a formação acadêmica de Skinner. Há, no Quadro 2, trechos que exemplificam tais subcategorias de equívocos históricos.

Ao contrário dessas informações divulgadas, o behaviorismo radical e a análise do comportamento, apesar de nunca terem representado o paradigma dominante na Psicologia, não deixaram de existir após o surgimento da psicologia cognitivista ou das críticas de Chomsky sobre a abordagem skinneriana ao comportamento verbal, pelo contrário, tem se desenvolvido constantemente por diversos caminhos (Correal, 2016; Smith, 2016); tradicionalmente, atribui-se a John B. Watson o título de fundador do behaviorismo, com seu texto intitulado "A Psicologia como o Behaviorista a vê" (1913); em relação às propostas tecnológicas, é preciso retificar que Skinner não foi o criador da primeira máquina de ensinar, tendo sido precedido por alguns pesquisadores, como Sidney Pressey (1926), mas criou uma nova máquina, baseada em conhecimentos sobre comportamento operante (Skinner, 1958); sobre a formação de Skinner, graduou-se em Literatura Inglesa na Hamilton College e realizou posteriormente mestrado e doutorado em Psicologia na Universidade de Harvard (Cunha \& Verneque, 2004).

\section{Quadro 2}

Apresentação de trechos que exemplificam as subcategorias de equívocos históricos.

\begin{tabular}{ll}
\hline Trecho que exemplifica a subcategoria & Subcategoria \\
\hline $\begin{array}{l}\text { É cedo para dizer se as ideias de Everett representam um golpe mortal para a teoria } \\
\text { chomskiana. (Não seria de todo impensável: o próprio Chomsky protagonizou um } \\
\text { episódio desses, quando pôs abaixo em 1959, com um único artigo, toda a psicologia } \\
\text { behaviorista de B. F. Skinner.) (Angelo, 2009, p. 8) }\end{array}$ & $\begin{array}{l}\text { Alegação do fim do } \\
\text { behaviorismo radical }\end{array}$ \\
\hline $\begin{array}{l}\text { Morreu sábado nos EUA, "pai da psicologia behaviorista" e autor de uma controversa } \\
\text { teoria sobre comportamento humano. (Folha de S.Paulo, 1990, p. C-1). }\end{array}$ & $\begin{array}{l}\text { Indicação de Skinner } \\
\text { como fundador do } \\
\text { behaviorismo }\end{array}$ \\
\hline $\begin{array}{l}\text { Um dia Skinner resolveu submeter sua filha, que tinha horror à matemática, ao mesmo } \\
\text { método empregado com as pombas: o resultado também foi excelente. O método } \\
\text { tomou o nome de Instrução Programada e, depois de algum tempo, o psicólogo acabou } \\
\text { por inventar uma máquina bastante simples e capaz de mecanizar o método. Neste dia, } \\
\text { nasceu então a primeira "máquina de ensinar". (Cunha, 1970, p. 30) }\end{array}$ & $\begin{array}{l}\text { Equívocos sobre } \\
\text { propostas tecnológicas }\end{array}$ \\
\hline $\begin{array}{l}\text { "A violência é o meu “box de Skinner" (alusão à caixa de vidro e antissetizada [sic] que } \\
\text { servia de berço à filha do sociólogo norte americano). (Sarraude, 1972, p. 27) }\end{array}$ & $\begin{array}{l}\text { Equívocos sobre a } \\
\text { formação acadêmica } \\
\text { de Skinner }\end{array}$ \\
\hline
\end{tabular}

Na Folha de S.Paulo houve um número consideravelmente maior de afirmações consistentes com os conceitos e a história da análise do comportamento e do behaviorismo radical $(\mathrm{N}=60)$, em comparação com os resultados de Azoubel e Abbud (2017). Em doze trechos houve citação correta a aspectos da teoria analítico-comportamental para justificar algum argumento, em 29 ocasiões foram apresentadas informações corretas acerca de aspectos históricos ou bibliográficos sobre Skinner e em dezenove parágrafos foram encontradas descrições corretas de aspectos conceituais. No Quadro 3 há trechos que exemplificam tais categorias.

Quadro 3

Apresentação de trechos que exemplificam as subcategorias de afirmações corretas.

\begin{tabular}{ll}
\hline Trecho que exemplifica a subcategoria & Subcategoria \\
\hline O Ensino Personalizado é um método novo de ensino, baseado em pesquisas de Psicologia & $\begin{array}{l}\text { Citação correta } \\
\text { para justificar } \\
\text { Experimental sobre o comportamento, desenvolvido pelo psicólogo americano Fred F. }\end{array}$ \\
$\begin{array}{ll}\text { Keller, a partir de estudos iniciados por Skinner, e teve sua primeira experiência realizada } \\
\text { entre nós, na Universidade de Brasília, a partir de 1963, coordenada pelos professores }\end{array}$ & \\
Carolina M. Bori e Rodolfo Azzi. Respeitando o ritmo de trabalho e assimilação particular de & \\
cada estudante, consegue obter 100\% de aproveitamento, o que tem assegurado um enorme & \\
sucesso em termos de resultados e objetivos alcançados. (Folha de S.Paulo, 1974, p. 20) & \\
\hline
\end{tabular}




\begin{tabular}{|c|c|}
\hline Trecho que exemplifica a subcategoria & Subcategoria \\
\hline $\begin{array}{l}\text { Nascido em 1904, em Susquehanna (nordeste dos EUA), Skinner foi atraído pelos estudos } \\
\text { do russo Ivan Pavlov sobre reflexos condicionados. Recebeu seu Ph. D. -equivalente ao } \\
\text { título de doutoramento nos EUA- em 1931, pela Universidade de Harvard, onde trabalhou } \\
\text { como pesquisador até 1936. Em 1936, Skinner foi lecionar na Universidade de Minnesota, } \\
\text { no estado de Minneapolis (norte dos EUA), onde escreveu “O Comportamento dos } \\
\text { Organismos", em 1938. (Ferreira, 1990, p. 6) }\end{array}$ & $\begin{array}{l}\text { Descrição correta } \\
\text { de aspectos } \\
\text { biográficos ou } \\
\text { bibliográficos }\end{array}$ \\
\hline $\begin{array}{l}\text { Skinner, o principal psicólogo da corrente behaviorista, é um cientista pouco lido e } \\
\text { raramente compreendido. Suas idéias são muito complexas e enfatizam a necessidade } \\
\text { de explicar qualquer comportamento, por mais simples que pareça, como resultado } \\
\text { da combinação de muitas causas. Os métodos da Análise do Comportamento foram } \\
\text { propostos por Skinner para destrinçar estas múltiplas causas e mostrar como elas se } \\
\text { combinam para determinar a conduta. Skinner escreveu um livro, "Sobre o Behaviorismo", } \\
\text { procurando mostrar que são falsas as afirmações mais difundidas a respeito do seu } \\
\text { pensamento, como por exemplo as seguintes: 1) ele ignora a consciência e os estados } \\
\text { mentais; 2) formula o comportamento simplesmente como um conjunto de respostas a } \\
\text { estímulos, representando assim a pessoa como um autômato, robô, boneco ou máquina; } \\
\text { 3) não dá lugar para intenção ou propósito. (Rose, 1990, p. 6) }\end{array}$ & $\begin{array}{l}\text { Exposição correta } \\
\text { de aspectos } \\
\text { conceituais }\end{array}$ \\
\hline
\end{tabular}

Em duas ocasiões, a Folha deu voz a analistas do comportamento, que puderam divulgar corretamente os conhecimentos da área. Maria Amélia Matos e Julio de Rose, dois reconhecidos analistas do comportamento brasileiros, escreveram 22 trechos no jornal, sendo todos conceitual e historicamente corretos. Mais notadamente, dezoito dos dezenove trechos categorizados como contendo descrição correta de aspectos conceituais foram escritos por esses autores. $\mathrm{O}$ trecho restante foi resultado de uma breve entrevista a Garry Martin, reconhecido analista do comportamento estrangeiro, realizada em 1978.

A categoria exposição correta de aspectos conceituais pode ser entendida como aquela que agrupou os trechos em que informações mais consistentes e importantes foram divulgadas, visto que explicitaram corretamente aos leitores aspectos conceituais da análise do comportamento, tantas vezes apresentados de forma equivocada (Azoubel \& Abbud, 2017; Gioia, 2001). Dado que a maioria $(94,7 \%)$ das ocorrências dessa categoria se deu em trechos escritos por dois analistas do comportamento, é possível salientar a importância da divulgação feita pelos especialistas no assunto, afinal, sem esses textos haveria apenas um trecho divulgando os conceitos da área corretamente. Parece importante que os próprios analistas do comportamento se encarreguem de comunicar o que a análise do comportamento tem a oferecer.

Dos trechos da categoria problematização sobre a análise do comportamento $e$ o behaviorismo radical, dezoito deles continham problematizações sobre a questão da liberdade e do controle do comportamento, enquanto dezoito apresentavam o confrontamento entre as propostas analítico-comportamentais e de outras abordagens, especialmente a psicanálise $(\mathrm{N}=10)$ e outras correntes filosóficas ou psicológicas $(\mathrm{N}=8)$. De forma geral, como é possível verificar nos exemplos do Quadro 4, eram apresentadas posições divergentes e anunciadamente polêmicas, mas não eram apresentadas informações adicionais que auxiliassem os leitores a assumirem uma posição embasada, a fim de resolver as questões problematizadas. 
Quadro 4

Apresentação de trechos que exemplificam as subcategorias de problematizações.

\begin{tabular}{|c|c|}
\hline Trecho que exemplifica a subcategoria & Subcategoria \\
\hline $\begin{array}{l}\text { Skinner já havia ido mais longe em “Walden 2", romance de 1948. O livro descreve uma } \\
\text { sociedade imaginária funcionando segundo os postulados behavioristas. Nela, não há } \\
\text { classes sociais, propriedade privada, violência ou privilégios. Este mundo, Skinner o } \\
\text { imaginava como resultante de condicionamentos complementares. Numa passagem, } \\
\text { o autor descreve uma cena em que cabras pastam no jardim de uma casa e tira disso } \\
\text { a seguinte conclusão: as cabras ficam alimentadas ao mesmo tempo em que fazem a } \\
\text { manutenção do jardim. "Walden” seria um país onde tudo funcionasse dessa forma. Os } \\
\text { críticos do "paraíso terrestre” proposto por Skinner diziam que seu preço era a redução dos } \\
\text { indivíduos a simples peças de uma "engenharia social” (expressão do próprio Skinner). } \\
\text { (Silva, 1990, p. E-7) }\end{array}$ & $\begin{array}{l}\text { Problematização sobre } \\
\text { liberdade e controle }\end{array}$ \\
\hline $\begin{array}{l}\text { Trabalhando na Califórnia desde 1962, Rogers atuou no Centro para Estudos da Pessoa, } \\
\text { em La Jolla, onde também morava. Sobre as teorias de B. F. Skinner - conhecidas como } \\
\text { comportamentalismo -, Rogers disse que "são excelentes para o conhecimento de } \\
\text { ratos e de macacos, mas não de pessoas". Skinner, por sua vez, dizia que Rogers e sua } \\
\text { psicologia humanista eram um "brilhante equívoco". Suas polêmicas sobre psicologia } \\
\text { educacional influenciaram muitas instituições de ensino. (Folha de S.Paulo, 1987, p. 14). }\end{array}$ & $\begin{array}{l}\text { Problematização sobre } \\
\text { as diferenças entre o } \\
\text { behaviorismo radical } \\
\text { e outras correntes de } \\
\text { pensamento }\end{array}$ \\
\hline
\end{tabular}

A categoria de críticas foi subdividida em sete subcategorias, exemplificadas no Quadro 5. Foram contabilizados dez trechos que criticaram a noção de controle e a falta de liberdade, oito trechos fizeram críticas positivas e dezessete trechos expuseram metacríticas, quatro trechos fizeram críticas à suposta superficialidade e um trecho colocou o behaviorismo radical como algo inferior às demais correntes psicológicas, vinte trechos colocaram Skinner e/ou o behaviorismo radical como sendo controverso ou até mesmo repudiado, 24 trechos colocaram Skinner e/ou o behaviorismo radical como influente.

Quadro 5

Apresentação de trechos que exemplificam as subcategorias de críticas.

\begin{tabular}{ll}
\hline Trecho que exemplifica a subcategoria & Subcategoria \\
\hline O sistema personalizado segundo o prof. Sodré está apoiado na psicologia da & Crítica positiva \\
aprendizagem proposta por Skinner, segundo a qual o aluno é tratado conforme & \\
suas tendências e aptidões. Deixando de ser simplesmente um número a mais entre & \\
outros, passando a ser tratado como indivíduo. (Folha de S.Paulo, 1973, p. 10). & \\
\hline
\end{tabular}

O que tem mais irritado psicólogos sociais voltados para a dialética e que lêem o antigo Skinner, é sua teimosia em ignorar a força do homem como agente da Crítica sobre o controle história. Ele parece estar sempre se dirigindo a agências governamentais, para fornecer-lhes as "dicas" necessárias para um "efetivo e funcional” controle sobre o comportamento dos homens ou de grupos de homens. Todavia, isso é totalmente contraditório, porque o ser humano, por ser o que é, consegue desenvolver sempre e mais as técnicas de contracontrole, na busca pela liberdade. (Cardoso, 1979, p. 65)

Há quem descarte a filosofia de Skinner como simplesmente tola. Ele é um grande psicologista, um dos maiores do mundo, ninguém contesta, mas de filosofia política não entende nada. Que fique com a "humanidade" de suas gaiolas, não com a humanidade verdadeira, que se escreve com H maiúsculo! (Reis, 1971, p. 38).

\begin{tabular}{ll} 
No Brasil de Skinner passamos a Rogers. Um pouco melhor. Com o “Tratamento & Atribuição de \\
Clínico da Criança Problema”, de Carl Rogers, temos, mais uma vez, um amplo & valor inferior \\
estudo sobre “o quanto é difícil tratar os problemas das crianças para os quais não há & \\
uma receita”. (Folha de S.Paulo, 1980, p. 45). & \\
\hline
\end{tabular}




\begin{tabular}{ll}
...continuação & Subcategoria \\
\hline Trecho que exemplifica a subcategoria & Metacrítica \\
\hline $\begin{array}{l}\text { Infelizmente, esse tributo acaba incorrendo no pecadilho daqueles que só conhecem } \\
\text { Skinner a partir da literatura secundária: caricaturar o behaviorismo radical como }\end{array}$ & \\
uma psicologia sem psiquismo. Uma visão anedótica, que transpira um certo & \\
humanismo de botequim ou uma certa etiqueta pseudo-intelectual que a ensina & \\
a torcer o nariz para o behaviorismo e para o positivismo sem saber do que se está & \\
falando. (Teixeira, 2005, p. 6). & \\
\hline Conheça Skinner, o 'pai do behaviorismo'. A Folha publica hoje duas páginas dedicadas & Controverso/ repudiado \\
ao pesquisador Burrhus Frederic Skinner, que morreu aos 86 anos sábado último. & \\
Skinner era o maior nome da psicologia behaviorista e um dos mais controvertidos & \\
pensadores deste século. Atacado pelos humanistas, foi acusado de ser um & \\
"psicólogo de ratos" e de conceber uma sociedade totalitária. (Silva, 1990, p. E-7) & \\
\hline Skinner conta hoje 67 anos e tem uma longa carreira de educador e pesquisador, \\
que começou em Minnesota, passou por Indiana e chegou afinal à Harvard, onde & Influente \\
desde 1948 leciona e pesquisa, havendo atingido o professorado pleno em 1958. & \\
$\begin{array}{l}\text { Durante essa carreira, iniciada em 1931, sua ocupação capital tem sido a psicologia } \\
\text { experimental. Celebrizaram-no as pesquisas sobre condicionamento operante ou }\end{array}$ & \\
instrumental. (Reis, 1971, p. 37) & \\
\hline
\end{tabular}

Pode-se notar que o número de metacríticas e de críticas positivas $(\mathrm{N}=25)$ foi superior ao número de críticas a aspectos negativos ( $\mathrm{N}=10)$, o que mostra preocupação dos autores em indicar que o behaviorismo radical é costumeiramente alvo de críticas indevidas. Ao analisar os trechos, pôde-se notar que as críticas feitas geralmente não apresentavam argumentação para sustentá-las.

Azoubel e Abbud (2017) haviam notado que na revista Veja, mesmo quando os autores trataram do behaviorismo radical, foi utilizado genericamente $o$ termo "behaviorismo", sem especificação do termo "radical", que caracteriza a proposta skinneriana.
Na Folha de S.Paulo, a proposta skinneriana foi chamada de behaviorismo radical em apenas cinco dos 228 trechos analisados. Em outros 26 trechos não foi possível identificar qual behaviorismo fora citado, em 25 situações o termo "behaviorismo" foi apresentado de forma genérica, mas era possível identificar se tratar do behaviorismo radical, e em duas ocasiões o termo foi usado para abordar o behaviorismo watsoniano (perspectiva que defende que todos os comportamentos são observáveis ou, ao menos, potencialmente observáveis). Podem ser verificados, no Quadro 6, exemplos para as subcategorias apresentadas.

\section{Quadro 6}

Apresentação de trechos que exemplificam as subcategorias de utilização genérica do termo "behaviorismo".

\begin{tabular}{|c|c|}
\hline Trecho que exemplifica a subcategoria & Subcategoria \\
\hline $\begin{array}{l}\text { Skinner - psicólogo norte-americano que abriu novas áreas dentro do } \\
\text { BEHAVIORISMO, criando toda uma corrente cujo interesse essencial é o estudo } \\
\text { dos meios de controlar o comportamento, com base no conceito de reforço } \\
\text { (i.e., qualquer fato que aumenta a probabilidade de um comportamento } \\
\text { anterior). (Folha de S.Paulo, 1970, p. 2). }\end{array}$ & $\begin{array}{l}\text { Identificável como tratando } \\
\text { do behaviorismo radical }\end{array}$ \\
\hline $\begin{array}{l}\text { "Behaviorismo", do inglês "behavior", comportamento. Eis a chave para entrar } \\
\text { na mente, essa entidade fugidia que há séculos escapa da investigação filosófica. } \\
\text { Pelo menos era assim que pensavam os behavioristas do início deste século, } \\
\text { como John Watson (1878-1958), que cunhou o termo em 1913; para os animais, } \\
\text { não existe como perguntar "o que você está sentindo?". O possível é apenas } \\
\text { estimulá-los e observar sua reação ao estímulo. Por que deveria ser diferente } \\
\text { com seres humanos? (Assis, 1990, p. E-6) }\end{array}$ & $\begin{array}{l}\text { Identificável como tratando } \\
\text { de outro behaviorismo }\end{array}$ \\
\hline
\end{tabular}


...continuação

Trecho que exemplifica a subcategoria

Subcategoria

Drama de horror de ratos amestrados e cujo líder, Ben, tem grande amizade com um garoto doentio. A polícia combate os roedores como pode, mas estes se

Não identificável

valem de sua agilidade para, ao mesmo tempo, fugir pelos esgotos e saquear os armazéns das redondezas. Sequela de "Calafrio", filme sobre o mesmo assunto que obteve sucesso quando do seu lançamento. Recomendado apenas para adeptos do behaviorismo. (Folha de S.Paulo, 1983, p. 38)

O uso genérico do termo "behaviorismo" não foi considerado um equívoco, mas é importante destacar que, devido à existência de diversas abordagens filosóficas e psicológicas que se enquadram sob esse rótulo geral (Zilio \& Carrara, 2016, 2017; Smith, 1986), tal prática pode induzir o leitor ao erro ou à confusão sobre o que estão tratando. Dois casos podem servir como exemplos dos possíveis efeitos prejudiciais desta confusão entre os diferentes behaviorismos: Guimarães (2003) apontou que há críticas de que a proposta skinneriana rejeitaria qualquer tipo de introspecção e de que se trataria de uma abordagem positivista baseadas em incompreensões sobre as diferenças entre behaviorismo radical e behaviorismo metodológico, enquanto Strapasson e Carrara (2008) afirmaram que o behaviorismo watsoniano tem sido erroneamente rotulado como behaviorismo metodológico (abordagem que se dedica exclusivamente ao estudo de eventos publicamente observáveis e exclui os comportamentos não observáveis de suas análises).

\section{Considerações finais}

De forma geral, foram encontrados trechos, em ordem decrescente de ocorrência das categorias, que fizeram críticas ao behaviorismo radical, que expuseram equívocos históricos e conceituais, que apresentaram algum aspecto correto sobre o behaviorismo radical, que apresentaram o behaviorismo de forma genérica e que problematizaram o behaviorismo radical. A partir das análises foi possível notar que as críticas, em geral, não foram acompanhadas de uma adequada justificativa dos argumentos apresentados, que os equívocos encontrados já foram apontados anteriormente por outros analistas do comportamento (e.g., Skinner, 1974); houve mesmo número de problematizações sobre a questão da liberdade e do controle do comportamento e sobre o confrontamento entre as propostas analítico-comportamentais e outras abordagens, principalmente a psicanálise; e que foi encontrado um número significantemente maior de apresentações de aspectos corretos do que o encontrado por Azoubel e Abbud (2017), com destaque para os textos escritos por analistas do comportamento, algo que também não foi encontrado na pesquisa anterior.

Para delimitar a existência de equívocos conceituais e históricos foram utilizados majoritariamente textos de Skinner (1950, 1953/1965, 1958, 1961/1955, $1973,1974,1981)$, que continham informações contrárias àquelas veiculadas nos trechos considerados equivocados. É relevante destacar que a obra de Skinner tem despertado ao longo dos anos interpretações divergentes, de forma que podem caber interpretações diferentes daquelas apresentadas aqui. Por conseguinte, pode ser produtivo em futuras pesquisas discutir os critérios e os argumentos apresentados neste trabalho para definir as afirmações como corretas ou incorretas. Além disso, em novos trabalhos, para esclarecer tópicos polêmicos, pode ser importante apresentar citações diretas de Skinner.

Um caminho proveitoso para novas pesquisas pode ser o de examinar como se dá o diálogo entre analistas do comportamento e pessoas leigas em análise do comportamento, realizado em meios de comunicação de massa ou em congressos de outras áreas. Afinal, pode ser relevante analisar quais termos são usados, como os conceitos básicos são abordados, de que maneira são apresentados dados de estudos científicos e, se possível, qual o impacto de suas colocações no público. Os dados produzidos por estudos desse tipo poderiam produzir uma reflexão sobre como apresentar as propostas analítico-comportamentais de maneira efetiva e coerente com seus princípios básicos.

Espera-se que a presente pesquisa auxilie os profissionais da área a identificar tópicos mal compreendidos, que necessitam especial atenção: a visão da análise do comportamento como uma abordagem defensora do controle, superada pelas teorias cognitivistas, capaz de explicar apenas comportamentos simples ou de animais não-humanos e interessada 
apenas em comportamentos observáveis. O desafio, então, deve ser comunicar corretamente as propostas analítico-comportamentais, salientando seu caráter de denúncia das relações de controle comportamental, de forma a auxiliar os sujeitos a se tornarem controladores dos seus próprios comportamentos, de uma ciência viva, em constante transformação e com tentativas de superar suas falhas e lacunas, de uma abordagem interessada em lidar com quaisquer comportamentos, simples ou complexos, observáveis ou não, mas especialmente os comportamentos humanos.

Na literatura da área, fora sugerido que os conceitos e tecnologias da análise do comportamento sejam apresentados a seus possíveis beneficiários com uma linguagem de fácil compreensão, adaptada aos seus interesses, que seus resultados bem-sucedidos sejam apresentados de forma clara e em comparação com os resultados produzidos por outras abordagens (Freedman, 2016), que os analistas do comportamento apliquem seus conhecimentos para formação de comunicadores por meio de cursos e palestras voltados a eles (Morris, 1985), que os especialistas publiquem suas contribuições em meios de comunicação não-acadêmicos ou em periódicos de outras áreas (Friman, 2014; Normand, 2014), que as associações entre esses pesquisadrores divulguem constantemente as possíveis contribuições analítico-comportamentais para a sociedade e que desenvolvam e divulguem tecnologias comportamentais capazes de solucionar problemas socialmente relevantes sem aumentar consideravelmente os custos econômicos e de resposta (Smith, 2016). Essas e outras estratégias devem ser amplamente discutidas, executadas e seus efeitos avaliados.

É importante destacar que Skinner, apesar de ter tentado diversas vezes comunicar-se com a grande mídia (Rutherford, 2004), atacou sistematicamente valores importantes para a maioria da população (e.g., sentimentos e livre-arbítrio) (Banaco, 1997; Coleman, 1982; Smith \& Woodward, 1996); evitou, em determinados momentos, o diálogo aberto com outros autores (Skinner, 1974) e promoveu suas ideias de maneira de maneira aguerrida (Coleman, 1982), por vezes atacando e ironizando ideias contrárias. Dessa maneira, não parece adequada uma visão vitimista sobre a percepção pública do behaviorismo radical.

Além disso, pode ter contribuído para a existência de incompreensões o fato de os analistas do comportamento terem cunhado uma nova terminologia, delineado métodos experimentais específicos e criado organizações e periódicos próprios, separados de outros psicólogos e de outras disciplinas científicas (Normand, 2014); o fato de esses especialistas possuírem, em sua história, registros da utilização de estratégias questionáveis por parte de profissionais analistas do comportamento como o uso de punição pelas então chamadas terapias aversivas e tentativas de alteração da orientação sexual de homossexuais, especialmente nas décadas de 1960 e 1970 (Kazdin, 1978). O exame e as tentativas de mudança destas barreiras podem ser executados em paralelo às análises críticas acerca das compreensões sobre análise do comportamento e behaviorismo radical, presentes entre os seus potenciais beneficiários e veiculadas na mídia.

O número relativamente pequeno de trechos permitiu que Azoubel e Abbud (2017) apresentassem todos os trechos analisados e uma análise pormenorizada dos equívocos presentes. Nesta pesquisa, foi encontrado um número grande de trechos, de forma que a análise não pôde ser realizada no mesmo grau de detalhamento. Por outro lado, o grande número de trechos analisados permitiu analisar quantitativamente as publicações ao longo dos anos. É possível que a comunidade dos analistas do comportamento se beneficie de uma análise mais pormenorizada dos trechos analisados aqui, de forma que recomendam-se extensões da presente pesquisa.

Recomenda-se que futuros estudos examinem o que foi publicado sobre behaviorismo radical e análise do comportamento em outros meios de comunicação para ampliar o debate aqui proposto. Sugerem-se análises de outros jornais e revistas de grande circulação, de revistas dedicadas exclusivamente à divulgação científica, de blogs e de páginas em redes sociais. Em especial, as redes sociais têm exercido papel cada vez mais importante na formação de opinião (Moraes \& Carneiro, 2018), de maneira que é importante estabelecer métodos adequados para o estudo das informações vinculadas nessas plataformas digitais.

O presente artigo abre possibilidades para diversos estudos que comparem o que é apresentado na mídia popular sobre behaviorismo radical e da análise do comportamento e o que é exposto sobre outras escolas da Psicologia e outras disciplinas científicas. Esses estudos poderiam ser relevantes para identificar semelhanças e diferenças entre o que é veiculado sobre as diferentes áreas, propiciando um debate sobre possíveis estratégias comuns para divulgação das diferentes teorias psicológicas e outras disciplinas científicas.

Para o delineamento de estratégias para divulgação de conhecimentos analítico-comportamentais, 
talvez seja importante que os analistas do comportamento informem-se das discussões atuais sobre divulgação científica (Vogt, Gomes \& Muniz, 2018), objetivando identificar possíveis contribuições procedentes de autores de outras áreas do conhecimento e, se possível, realizar projetos de maneira integrada com outros cientistas. Afinal, o "problema de comunicação" não parece ser característica exclusiva da análise do comportamento.

Neste artigo, foi tomada a decisão metodológica de categorizar os trechos encontrados por meio da leitura conjunta, discussão e consenso entre os pesquisadores ao invés de categorizar uma mostra dos trechos por um pesquisador independente e posterior cálculo da concordância entre ambos os pesquisadores. Considerou-se que, desta forma, o procedimento seria mais inclusivo, na medida em que os dois pesquisadores trabalhariam de maneira semelhante durante o processo, poderia produzir reavaliação constante das categorias de análise e poderiam principalmente ser levantadas, a partir do diálogo, diversas questões sobre o problema de pesquisa investigado, enriquecendo os elementos para a discussão dos resultados. O debate sobre qual método pode ser mais produtivo (Laurenti, Lopes \& Araujo, 2016) para analisar textos e avaliar a fidedignidade destas análises é um tópico que merece discussões metodológicas mais aprofundadas em estudos futuros.

\section{Referências}

Angelo, C. (2009, 1 de fevereiro). O iconoclasta. Folha de S.Paulo, 8-9.

Assis, J. P. (1990, 25 de agosto). Psicólogo sonhava com uma "física do pensar". Folha de S.Paulo, E-6.

Arntzen, E., Lokke, J., Lokke, G., \& Eilertsen, D. E. (2010). On misconceptions about behavior analysis among university students and teachers. The Psychological Record, 60(2), 325-336. https://doi.org/10.1007/BF03395710

Azoubel, M. S., \& Abbud, G. M. (2017). (Im)posturas jornalísticas: incompreensões da revista Veja sobre BF Skinner. Temas em Psicologia, 25(1), 181-192. https://dx.doi.org/10.9788/TP2017.1-12

Banaco, R. A. (1997). Podemos nos beneficiar das descobertas da ciência do comportamento? In R. A. Banaco (Org.), Sobre comportamento e cognição: aspectos teóricos, metodológicos e de formação em Análise do Comportamento e terapia cognitiva (pp. 543-555). Santo André, SP: ARBytes.

Bueno, W. C. (2010). Comunicação científica e divulgação científica: aproximações e rupturas conceituais. Informação \& Informação, 15(1), 1-12.

Cardoso, I. A. (1979, 18 de fevereiro). Para controlar o ser humano. Folha de S.Paulo, 65.

Coleman, S. R. (1982). B. F. Skinner: Systematic iconoclast. The Gamut, 6, 53-75.

Correal, T. E. P. (2016). El destino del Análisis de la Conducta. Acta Comportamentalia, 24(2), 153-168.

Cunha Jr., M. (1970, 21 de junho). O estudo agora ficou mais fácil, você acredita? Folha de S.Paulo, 30.

Cunha, R. N., \&Verneque, L, P. S. (2004). Centenário de B. F. Skinner (1904-1990): uma ciência do comportamento humano para o futuro do mundo e da humanidade. Psicologia: Teoria e Pesquisa, 20(1), 93-94. https://dx.doi.org/10.1590/ S0102-37722004000100014

Ferreira, F. R. (1990, 21 de agosto). Morre aos 86 anos o pai do behaviorismo. Folha de S.Paulo, 6.

Folha de S.Paulo. (1970, 15 de fevereiro). As palavras que explicam a psicologia. Folha de S.Paulo, 2.

Folha de S.Paulo. (1973, 25 de agosto). Experiência didática faz sucesso na UFP. Folha de S.Paulo, 10.

Folha de S.Paulo. (1974, 9 de junho). Amanhã a reunião do ensino individual. Folha de S.Paulo, 20.

Folha de S.Paulo. (1980, 2 de março). Carl Rogers, um bom passo à frente de Skinner. Folha de S.Paulo, 45.

Folha de S.Paulo. (1983, 15 de dezembro). Ben, o rato assassino. Folha de S.Paulo, 38.

Folha de S.Paulo. (1987, 7 de fevereiro). Morreu o psicólogo norte-americano Carl Rogers. Folha de S.Paulo, 14.

Folha de S.Paulo. (1990, 21 de agosto). Morre o "pai do behaviorismo". Folha de S.Paulo, C-1.

Folha de S.Paulo. (1991, 8 de abril). Ciência foi dominada pela filosofia desde Aristóteles. Folha de S.Paulo, 7.

Freedman, D. H. (2016). Improving public perception of behavior analysis. The Behavior Analyst, 39(1), 89-95. https://dx.doi.org/10.1007/s40614-015-0045-2 
Friman, P. C. (2014). Publishing in journals outside the box: attaining mainstream prominence requires demonstrations of mainstream relevance. The Behavior Analyst, 37(2), 73-76. https://dx.doi.org/10.1007/s40614-014-0014-1

Gioia, P. S. (2001). A abordagem behaviorista radical transmitida pelo livro de psicologia direcionado à formação de professores (Tese de doutorado). Pontifícia Universidade Católica de São Paulo, São Paulo, SP.

Guimarães, R. P. (2003). Deixando o preconceito de lado e entendendo o behaviorismo radical. Psicologia: Ciência e Profissão, 23(3), 60-67. https://dx.doi.org/10.1590/S1414-98932003000300009

Kazdin, A. E. (1978). History of behavior modification: experimental foundations of contemporary research. Baltimore, MD: University Park Press.

Laurenti, C., Lopes, C. E., \& Araujo, S. F. (Eds.). (2016). Pesquisa teórica em psicologia: aspectos filosóficos e metodológicos. São Paulo, SP: Hogrefe.

Leite, R. C. C. (1983, 5 de fevereiro). O louva-a-deus e sua noiva barba-azul. Folha de S.Paulo, 20.

Leminski, P. (1986, 8 de janeiro). Para passar o vestibular. Folha de S.Paulo, 38.

Micheletto, N., \& Sério, T. M. D. A. P. (1993). Homem: objeto ou sujeito para Skinner? Temas em Psicologia, 1(2), 11-21.

Miraldo, C. M. M. (1985). Conhecimento e crenças de estudantes de psicologia acerca da análise experimental do comportamento (Dissertação de mestrado). Universidade de São Paulo, São Paulo, SP.

Modgil, S., \& Modgil, C. (1987). B. F. Skinner: consensus and controversy. Philadelphia, PA: The Falmer Press.

Moraes, E. C., \& Carneiro, E. M. (2018). In V. Vogt, M. Gomes, \& R. Muniz (Eds.), ComCiência e divulgação científica (pp. 189-198). Campinas, SP: Unicamp.

Morris, E. K. (1985). Public information, dissemination, and behavior analysis. The Behavior Analyst, 8(1), 95-110. https://dx.doi.org/10.1007/BF03391916

Normand, M.P. (2014). Opening Skinner's box: an introduction. The Behavior Analyst, 37(2), 67-68.https://dx.doi.org/ $10.1007 / \mathrm{s} 40614-014-0016-\mathrm{z}$

Pedrosa, C. E. F., \& Santos, P. S. (2016). Análise crítica do discurso e mídia: estudo das erratas em revistas de divulgação científica e sua (não) aplicabilidade em sala de aula. Revista do GELNE, 14(1), 195-213.

Pereira, O. (1981, 5 de julho. A oposição e a questão militar. Folha de S.Paulo, 6.

Pessotti, I. (2016). Análise do comportamento e política. Revista Brasileira de Terapia Comportamental em Cognitiva, 28, 95-103. https://dx.doi.org/10.31505/rbtcc.v18i0.848

Pressey, S. L. (1926). A simple apparatus which gives tests and scores-and teaches. School and Society, 23(586), 373-376.

Ramon, F. (2008, 30 de novembro). Sinal vermelho. Folha de S.Paulo, 8.

Reis, J. (1971, 24 de outubro). No condicionamento operante a chave de uma sociedade verdadeiramente feliz (para isso seria preciso acabar com os conceitos de liberdade e dignidade). Folha de S.Paulo, 37-38.

Righetti, S. (2018). Ciência na mídia: onde estão os estudos de pesquisadores brasileiros? In V. Vogt, M. Gomes, \& R. Muniz (Eds.), ComCiência e divulgação científica (pp. 23-29). Campinas, SP: Unicamp.

Rodrigues, M. E. (1999). Algumas concepções de profissionais de educação sobre behaviorismo. In R. Kerbauy \& R. C. Wielenska, R. C. (Eds.), Sobre comportamento e cognição (pp. 240-250). Santo André, SP: ARBytes.

Rodrigues, M. E. (2006). Behaviorismo: mitos, discordâncias, conceitos e preconceitos. Educere et Educare, 1(2), 141-164.

Rose, J. C. (1990, 25 de agosto). A mente e a liberdade para Skinner. Folha de S.Paulo, 6.

Rutherford, A. (2004). A “visible scientist”: BF Skinner's Writings for the Popular Press. European Journal of Behavior Analysis, 5(2), 109-120. https://dx.doi.org/10.1080/15021149.2004.11434237

Sarraude, C. (1972, 5 de julho). "Macbeth”, cidadão Kane ou camundongo Mickey? Folha de S.Paulo, 27.

Schwartsman, H. (2013, 17 de fevereiro). Lancheiras caninas. Folha de S.Paulo, A2.

Silva, F. B. (1990, 25 de agosto). Herança filosófica ainda assombra humanistas. Folha de S.Paulo, E-7.

Skinner, B. F. (1950). Are theories of learning necessary? Psychological review, 57(4), 193-216. https://dx.doi.org/10.1037/ h0054367 
Skinner, B. F. (1958). Teaching machines. Science, 128(3330), 969-977.https://dx.doi.org/10.1126/science.128.3330.969

Skinner, B. F. (1961). Freedom and the control of men. In B. F. Skinner, Cumulative record (pp. 3-18). New York: Appleton-Century-Crofts. (Trabalho original publicado em 1955)

Skinner, B. F. (1965). Science and human behavior. New York: The Free Press. (Trabalho original publicado em 1953)

Skinner, B. F. (1973). Answers for my critics. In H. Wheeler (Ed.), Beyond the punitive society (pp. 256-266). San Francisco, CA: W. H. Freeman.

Skinner, B. F. (1974). About behaviorism. New York: Alfred A. Knopf.

Skinner, B. F. (1981). Selection by consequences. Science, 213(4507), 501-504.https://dx.doi.org/10.1126/science.7244649

Smith L. D. (1986). Behaviorism and logical positivism: a reassessment of the alliance. Stanford, CA: Stanford University Press.

Smith, L. D., \& Woodward, W. R. (1996). B. F. Skinner and behaviorism in American culture. New Jersey: Associated University Press.

Smith, J. M. (2016). Strategies to position behavior analysis as the contemporary science of what works in behavior change. The Behavior Analyst, 39(1), 75-87. http:// doi.org/10.1007/s40614-015-0044-3

Stamirowski, O. L. (1990, 2 de setembro). Painel do leitor. Folha de S.Paulo, A-3.

Strapasson, B. A., \& Carrara, K. (2008). John B. Watson: behaviorista metodológico? Interação em Psicologia, 12(1), 1-10. https://dx.doi.org/10.5380/psi.v12i1.9120

Teixeira, J. F. (2005, 13 de março). Auto-ajuda para as mentes. Folha de S.Paulo, 6.

Todorov, J. C. (2003). Science and Human Behavior translated into Portuguese: Ciência e Comportamento Humano. Journal of the Experimental Analysis of Behavior, 80(3), 341-343. https:// dx.doi.org/10.1901/jeab.2003.80-341

Vogt, C., Gomes, M., \& Muniz, R. (Eds.). (2018). ComCiência e divulgação científica. Campinas, SP: Unicamp.

Watson, J. B. (1913). Psychology as the behaviourist views it. Psychological Review, 20(2), 158-177. https://dx.doi. org/10.1037/h0074428

Weber, L. N. D. (2002). Conceitos e pré-conceitos sobre o behaviorismo. Revista PsicologiaArgumento, 20(31), 29-38.

Zilio, D., \& Carrara, K. (2016). Behaviorismos: reflexões históricas e conceituais (Vol. 1). São Paulo, SP: Centro Paradigma de Ciências e Tecnologia do Comportamento.

Zilio, D., \& Carrara, K. (2017). Behaviorismos: reflexões históricas e conceituais (Vol. 2). São Paulo, SP: Centro Paradigma de Ciências e Tecnologia do Comportamento.

\section{Marcos Spector Azoubel}

Doutor em Psicologia Experimental: Análise do Comportamento pela Pontifícia Universidade Católica de São Paulo (PUC-SP), São Paulo - SP. Brasil

E-mail:mazoubel@gmail.com

(1) Orcid ID: https:// orcid.org/0000-0002-0785-9761

\section{André Thiago Saconatto}

Doutor em Psicologia Experimental: Análise do Comportamento pela Pontifícia Universidade Católica de São Paulo (PUC-SP), São Paulo - SP. Brasil

E-mail: andre.saconatto@gmail.com

(1) Orcid ID: https:// orcid.org/0000-0002-4365-750X

Endereço para envio de correspondência:

Laboratório de Psicologia Experimental, PUC-SP, Rua Bartira, 387, Perdizes, São Paulo-SP. CEP: 05009-000.

Recebido 22/12/2017

Aceito 07/03/2019 
Received 22/12/2017

Approved 07/03/2019

Recibido 22/12/2017

Aceptado 07/03/2019

Como citar: Azoubel, M. S., \& Saconatto, A. T. (2020). Concepções sobre o Behaviorismo Radical nas Publicações da Folha de S.Paulo. Psicologia: Ciência e Profissão, 40, 1-17. https://doi.org/10.1590/1982-3703003189472

How to cite: Azoubel, M. S., \& Saconatto, A. T. (2020). Conceptions about Radical Behaviorism in Folha de S.Paulo's Publications. Psicologia: Ciência e Profissão, 40, 1-17. https://doi.org/10.1590/1982-3703003189472

Cómo citar: Azoubel, M. S., \& Saconatto, A. T. (2020). Concepciones acerca del Conductismo Radical en las Publicaciones de la Folha de S.Paulo. Psicologia: Ciência e Profissão, 40, 1-17.

https://doi.org/10.1590/1982-3703003189472 